\title{
Assessment of plant secondary metabolites in oil palm seedlings after being treated with calcium, copper ions and salicylic acid
}

\begin{abstract}
The effect of calcium, copper ions and salicylic acid (SA) amendment on the incidence of basal stem rot and activity of secondary metabolites in oil palm seedlings were investigated in glasshouse study. Disease incidence (DI) in positive control (T8) was $75 \%$ at nine months after inoculation (9 MAI). However, weekly pre-immunisation with $\mathrm{Ca} 2++\mathrm{Cu} 2++\mathrm{SA}$ prior to inoculation significantly suppressed DI and delayed disease onset as noted in T7. In the present study, the lowest \%DI was observed in T7 (15\%) followed by T1, T5, T6, T3, T4 and $\mathrm{T} 2$. The $\mathrm{Ca} 2+, \mathrm{Cu} 2+$ and SA amendments were resulted in earlier and higher accumulation of plant secondary metabolites as noted in leaves, stems and root tissues in response to invasion by Ganoderma boninense. High total phenolic content concentration was detected in T7 (leaf: $233.38 \pm 0.12 \mathrm{mg} / \mathrm{g}$; stem: $132.78 \pm 0.04 \mathrm{mg} / \mathrm{g}$ and root: $86.98 \pm 0.28 \mathrm{mg} / \mathrm{g}$ ). Similar trend was obtained in peroxidase activity, total lignin content and hydrogen peroxide scavenging activity. These results suggested that it could be due to the accumulation of phenolics, peroxidase activities, lignin content and hydrogen peroxide scavenging activities in oil palm seedling tissues which might have collectively contributed to induce resistance against $\mathrm{G}$. boninense.
\end{abstract}

Keyword: Basal stem rot disease; Plant secondary metabolites; Calcium; Copper ions; Salicylic acid 